\title{
Hofstede Revisited: Is Making the Ecological Fallacy when Using Hofstede's Instrument on Individual Behavior Really Unavoidable?
}

\author{
Tor Grenness \\ Department of Communication, Culture and Languages \\ BI Norwegian Business School \\ 0042 Oslo, Norway \\ E-mail: tor.grenness@bi.no
}

Received: January 17, 2012

Accepted: February 17, 2012

Published: April 1, 2012

doi:10.5539/ijbm.v7n7p75

URL: http://dx.doi.org/10.5539/ijbm.v7n7p75

\begin{abstract}
This paper suggests that avoiding the ecological fallacy is - under certain circumstances - possible. One problem in (cross-cultural) research is that there are often two levels of theorizing (individual and country) that needs to be taken into account when data are being analyzed and conclusions are drawn. Typically, as is the case with Hofstede's (1980) well-known research, cultural values are measured on country level. Consequently, researchers who make causal inferences from such group data to individual behaviors are making the ecological fallacy, i.e they (most often) wrongly assume that relationships observed for groups necessarily hold for individuals. If, however, a method could be found that could help determining how individuals behave from the study of aggregated data, the usefulness of Hofstede's research (and research on aggregated data in general) from a manager's point of view would definitely increase.
\end{abstract}

In this paper the problem of the ecological fallacy, as well as different methods of avoiding it is discussed, and a particular solution of the problem is suggested.

Keywords: Problem of ecological fallacy, Cross-cultural research, Hofstede's study, Possible solution

\section{Introduction}

Studies of management and organizational behavior are typically based on statistical inference. Studies of e.g. management styles or employee satisfaction are conducted as sample studies, i.e. the results are based on a sample of the population of interest, and then generalized to the population. As is commonly known, to what degree results from a sample survey are valid for the population relies on the sampling procedure. Not quite so obvious, however, is the fact that such inference is not a one-way street. It is - under certain circumstances possible to infer, or rather deduce, from a sample to an individual. Which, of course, brings us directly into the ecological fallacy-discussion, i.e. to what degree it is possible to draw conclusions on individual behavior based on group- or aggregated data.

Typically this problem occurs in studies of e.g. electoral behavior (Macdonald \& Heath, 1996) and in epidemiology (Schwartz, 1994), but the issue of (making the) ecological fallacy actually runs across all "social sciences" and has been addressed in, for example, studies of primary education (Higgs, Higgs, Bellin, Farrell, \& White, 1997), marketing (Armstrong, 1996), and in studies of organizations and management, not least when the focus of the study is to compare attitudes or behaviors across nations, see e.g. Hofstede, (1980), Schaffer and Riordan (2003).

In fact, almost from the time Hofstede's seminal work Culture's Consequences (1980) was published, the danger of making the so called "ecological fallacy", i.e. making statements of individual behavior based on data aggregated on a country level, has been discussed (Bond, 2002; Dorfman \& Howell, 1988; Robinson, 1983) , and recently again by Hofstede himself (2011). Hofstede's concern with the problem goes all the way back to his original study, as he states in the first edition of "Culture's consequences" (Hofstede, 1980, p. 400) that:"... The results (i.e. documenting cultural differences) are meant to be analyzed ecologically, not individually" (the italics are Hofstede's). Hofstede's primary concern, then, is not with how individuals differ, but how societies differ, - a rather vital fact which has been overlooked by a good many of Hofstede's readers as well as by 
scholars using Hofstede's frameworh in their own cross-cultural studies. For example, a recent article published in "Cross Cultural Management: An International Journal" (Hofstede, 2011), made Hofstede to write the following: "The article confuses the individual and the national level of analysis; in fact the author does not show awareness that such a thing as a level of analysis exists".

In spite of Hofstede's warning, however, the question of to what extent Hofstede's dimensions can not only be applied to comparing countries, but also to distinguishing among individuals, continue to deserve attention (Hoppe, 1990; Migliore, 2011). From a manager's point of view, it is obviously desirable to be able to identify universal dimensions that can do both, since managers tend to be primarily concerned with individual behavior. If this is not the case with Hofstede's framework, the usefulness of his work from a manager's point of view is somewhat limited as it does not provide any insight in individual differences related to e.g. vital areas like motivation and commitment. Dorfman and Howell (Dorfman \& Howell, 1988, p. 130) put it this way: "The ecological level of analysis severely restricts the meaningfulness and usefulness for researchers who operate at the micro-level of analysis". In order to overcome these shortcomings, Dorfman and Howel's strategy were to develop an instrument to measure dimensions of national culture that have impact on work-related values and other management process issues. Their goal was to extend the measurement of culture, usually conceived as an attribute at the societal level to the individual level. Based on the work of Hofstede and others, scales were developed which measure five important cultural dimensions and where individuals who strongly believed in these key cultural dimensions were compared to individuals who indicated weak beliefs in these values. Although their work led to promising results, it has to be noted that the main objective of their empirical study was to determine the impact of cultural dimensions on certain relationships between leader behaviors and criterion variables. The culture measures were thus used as moderators between various leader behaviors and satisfaction with work and supervision, organizational commitment, and job performance.

It also has to be noted, as Migliore (2011) emphasized in her response to Hofstede's critique, that Hofstede's own research (Hofstede \& McCrae, 2004) in fact revealed relationships between dimensions of culture and personality factors, which at least may be taken as an indicator of a inter-relational aspect of personality and culture. This reasoning is, however, not accepted by Kitayama (2002, p. 92), who states that “ $\ldots$ when Japanese and Americans are different in a certain psychological characteristic, say, self-esteem, the difference is not caused by culture".

What this tells us is that the problem of finding methodological sound solutions that enables the researcher to draw conclusions of individuals based on group data, - that is; which enable the researcher interested in individuals, but only has access to aggregated data, to avoid or at least reduce the danger of the ecological fallacy, remains by and large unsolved.

Although the problem of making the ecological fallacy is well known from a wide range of textbooks, there is none the less various conceptions of what the problem implies as well as many different suggestions on how to deal with this problem (Freedman, 1999; King, 1997) What can generally be said is that there seems to be a common conception that it refers to a logical fallacy inherent in making causal inferences from group data to individual behaviors (Blalock, 1964; Cook et al., 1979), but because different textbooks deals with the problem somewhat differently, and not least because the ecological fallacy is indeed a typical issue in research on cross-cultural or comparative management (Schaffer \& Riordan, 2003; Smith, Peterson, \& Schwartz, 2002), we think that revisiting Hofstede and the problem of making the ecological fallacy will still be of importance for scholars within this field as well as for managers working internationally.

Consequently, our first objective (1) will be to try to find out what, exactly, do we mean when we refer to the "ecological fallacy"?

Next (2) the question of to what extent Hofstede's four dimensions can not only be applied to comparing countries, but also to distinguishing among individuals will be discussed.

Implicit in this discussion, the question (3) whether it is possible to deal with the ecological fallacy-problem in a general and methodological sound manner and thus improve the benefit of aggregated data will be raised.

These three problems create the base for discussions in this article.

The ecological fallacy - what does it really mean, and why is it of more than pure academic importance?

As was briefly mentioned above, the ecological fallacy is assumed to occur when relationships are estimated at one level of analysis (e.g. collectivities) and then extrapolated to another level (e.g. individuals). In his classic study, William Robinson (1950) effectively demonstrated the consequences of the ecological fallacy. Focusing on the relationship between literacy and place of birth in the 1930ies, Robinson compared the geographical 
regions of the United States. He found that regions with higher percentages of foreign-born people had higher literacy rates than regions with lower percentages of foreign-born persons. But when he subsequently examined the same relationships at the individual level, he came up with the opposite result: native-born individuals were more literate then foreign-born. The ecological correlation gives the wrong inference; the sign of the correlation is positive because the foreign-born tend to live in regions where the native-born are relative literate.

Robinson was not the first scholar to note the pitfalls of inferences from the group to the individual level analysis, but he was the first to bring the problem of cross-level inference forcefully to the attention of empirically minded social scientists (Langbein \& Lichtman, 1979). One consequence of Robinson's article was a general distrust towards the use of aggregated data, disregarding the fact that ecological inferences are both necessary and possible - even when availability of individual data is not possible. Langbein and Lichtman (op.cit: 9) put it this way: "In 1950, life became more difficult for social scientists attempting the quantitative study of individual behavior". And, we might add, from the 1980ies also for managers who seemingly had read Hofstede, but who conveniently attributed national cultural traits to individuals ("In our Mexican plant delegation is out of the question. Mexicans, you know, avoid uncertainty").

Generally, attempts to study individuals through the analysis of aggregated units rested on the unspoken assumption that statistical measures computed for these units would have the same value as corresponding measures computed from individual level data, "personal values are cultural values writ small". Robinson shredded this assumption, and it was Robinson who popularized the term "ecological fallacy" to describe any incorrect inference about individual behavior from grouped data.

Contrary to the pessimistic claims in the methodological literature (since Robinson, 1950), researchers in many fields of academic inquiry, as well as practitioners, routinely try to make inferences about attributes of individual behavior from aggregated data.

Intuitively many would argue that results from an aggregated level quite often indicate how things are on an individual level. For example: Hofstede's study shows that the Norwegian score on the Masculinity index is extremely low, i.e. that so called feminine values are dominating in Norway (Hofstede, 1980). A logical and interesting question would thus be: Does this mean that Norwegian managers as individuals also hold these feminine values? It would be my best guess that researchers who have been studying Norwegian managers would answer yes to that question. And in most cases would probably be right about it simply because most people will actively strive to coordinate his or hers behaviors with the pertinent cultural systems of practices and public meanings (Kitayama, 2002). None the less it is still important to bear in mind that even if several studies seem to verify the general tendency among Norwegian (and Scandinavian) managers to act according to feminine values (Grenness, 2000; Grenness, 2003, 2011; Schramm Nielsen, Sivesind, \& Lawrence, 2004), this is still to be regarded as a cultural norm, not necessarily a characteristic of the personality of individual Norwegian managers (Bjerke, 1999). Even if we take Bjerke's words into consideration, what is coming out of this is something of a paradox because the statement that individual Norwegian managers hold feminine values, which implicates an ecological fallacy, and thus is obviously logically invalid, may still be empirically valid.

This paradox can be illustrated as follows:

Matrix showing nine theoretical situations where empirically valid or invalid, (but logically invalid) conclusions can be drawn concerning the correlation between $x$ and $y$ across levels of analysis: (adapted from Halle, 1976)

\section{Insert Table 1 here}

What this implies is that we have no way of knowing how two variables will correlate (if at all) on an individual level (n), given that we know how they correlate on an aggregated level $(n+1)$. If we for instance look at the second situation illustrated above, it tells us that we have a positive correlation on the ecological level (e.g. between Masculinity and Achievement Orientated motivation), but drawing the conclusion that every manager in a country with a high score on Masculinty will also be highly achievement motivated is both empirically and logically wrong. Actually we could be empirically right about it, but the point to be made is that as long as we only know how the correlation between $\mathrm{x}$ and $\mathrm{y}$ is on an aggregated level, we have no way of predicting it on an individual level. We could be right, but we could just as well be wrong.

Another point to be made is that even if we are proved right, there may be other problems hidden within the process of moving from one level of analysis to another that need to be solved - or at least discussed. One has to do with the fact that "The demystification of cross-level bias begins with the recognition that an aggregate variable often measures a different construct than its name-sake at the individual level" (Firebaugh, 1978, p. 500). 
What this implies is that the construct referenced on the ecological level relates to the context or social environment in which individuals live, distinct from the attributes of those individuals (Blau \& Blau, 1982). Thus masculinity as a country characteristic and masculinity as an individual characteristic may exert different, independent effects on behavior. The same could be said for e.g. the word "democratic" as it is used to characterize both a democratic form of government and a democratic leader. What this implies is that we also face the danger of a "semantic fallacy" adding to the ecological fallacy. Consequently individual and aggregate correlations of variables could be discrepant, meaning that examining problems associated with construct validity may prove a useful addition to understanding cross-level inference (Schwartz, 1994).

Or we could put it this way: "In shifting from one unit of analysis to another, we are very likely to affect the manner in which outside and possibly disturbing influences are operating on the dependent and independent variables" (Blalock, 1964, p. 97). Consequently, the problem of inferring from aggregated to individual data may also be due to a failure to specify the correct model and not to an inherent logical fallacy.

Important as this may be in dealing with aggregated data, it is none the less in the literature a common agreement that the fallacy of the wrong level is generally the result when the researcher chooses his research case from a (social system) level that does not fit his conceptual model (Babbie, 1986; Frankfort-Nachmias \& Nachmias, 1992). The ecological fallacy, thus, in general consists in assuming that properties found to be correlated at a higher level are correlated, i.e. found within the same unit, at the lower level. With reference to Hofstede, this is the case if the researcher draws conclusion of individual managers' behavior based on country scores. At the same time this is tempting both because of the practical usefulness of such conclusions, but also because the researcher himself has an intuitively feeling, often based on experience, that such conclusions are not empirically invalid. But because conclusions based on intuition and personal experience are generally not highly valued in social science research, an important question would be:

Do aggregated data necessarily represent an obstacle for drawing methodologically sound conclusions about individual behavior, or is it possible to circumventing the problems that Robinson raised?

\section{Possible solutions}

In their highly referenced article, "Ecological Inference", Langbein and Lictman (1979) provide several possible solutions to the problem, and the use of ecological regression is regarded by the authors as the most useful means of determining how individuals behave from the study of aggregated data. This does not mean, however, that they viewed ecological regression to be the optimal solution, rather they viewed it to be the best of several bad alternatives. Furthermore, the use of ecological regression - being a highly technical procedure - demands a certain level of mathematical skills in order to get the full benefit of it. Also, as is stated by several statisticians, there are certain (restrictive) assumptions that have to be met in order to get the full benefit of this procedure, in particular the so called "constancy assumption" (Freedman, 1999). A much referenced version of this is that the statistical behavior of a demographic group is not allowed to depend of the area of residence (King, 1997). While the constancy assumption may work in studies of e.g. voting behavior within a certain geographical unit, the problem of managers' behavior in cultural contexts is a totally different matter. In fact, the cultural model turns the constancy assumption on its head as it is culture, not demography that is assumed to count for a certain constancy of behavior.

When this is the case, ecological regression ought to be replaced by the so called "neighborhood model" (Freedman, 1999). According to this model, behavior is determined by geography, not demography.

Because Hofstede uses nations as his cultural units, the neighborhood model intuitively seems like a better alternative than (varying forms of) ecological regression if we want to infer from an ecological to an individual level.

Still, a review of the different methods developed in order to overcome the problem of "the ecological fallacy" leaves one with the notion that for one thing these methods are highly technical (this goes for the neighborhood model as well) and in general rest upon a set of assumptions that not always fit with the situation at hand.

Consequently we think that there still ought to be room for a discussion of alternative ways of dealing with this problem which not least are easier to grasp for managers where the focus is on practical day-to-day problems such as how to improve job satisfaction, commitment and motivation among members of an international workforce.

\section{Method}

In our discussion of the question stated above, we will use three data sources: The first one (1) is the aggregated results of Hofstede's study concerning Norwegian work values. The second one (2) is the results a study of 
values of Norwegian managers (Grenness, 2000), which is based on Hofstede's research instrument, and the third one (3) is the results a qualitative study of Scandinavian (mostly Norwegian) managers' perception of their own behavior (Grenness, 2003). In order to discuss the ecological fallacy-problem we will not use the Norwegian country-level results on all four dimensions of Hofstede's framework, but will, for reasons to be revealed below, use the results on the Masculinity - Femininity dimension only.

\section{Data sources and results}

\section{Data source I: Results of Hofstede's Norwegian study on the Masculinity dimension}

Hofstede's development of the four cultural dimensions was based on a Factor analysis of the aggregated data (an ecological factor analysis) from the 14 Work Goals (items) across 40 countries. As a result of his analysis, two factors explaining $46 \%$ of the total variance of the country means were found (Hofstede, 1980). One of these factors, which Hofstede labeled the Social/Ego factor, became the basis for the Masculinity - Femininity dimension. The reason for the name is - as Hofstede himself puts it - $(1991$, p. 82) that ".... This dimension is the only one which the men and women among the IBM employees scored consistently differently". But he also adds,"...Except in countries at the extreme feminine pole".

Following his own warning about the ecological fallacy, Hofstede's first statement obviously has to refer to gender differences at an aggregated level. Furthermore, in order to test the empirical validity of his second statement, Norway is almost an ideal case.

In Hofstede's study Norway's score on the Masculinity dimension is 8 (on a scale ranging from $0-100$ ), which is the second lowest of all, and which no doubt places Norway at the extreme feminine pole. According to Hofstede (1980), a low score on the Masculinity dimension indicates a general preference for relationships, modesty, caring for the weak, and the quality of life as opposed to material success and progress, which are preferred in countries with a high score on this dimension. With reference to organizational behavior, what is of importance in"feminine poles-countries" based on the above mentioned factor analysis, is to:

- Work with people who cooperate well with one another

- Have security of employment

While it is of less importance to:

- Have an opportunity for advancement to higher level jobs

- Have an opportunity for higher earnings

(Hofstede, 1991, items taken from the 1994 Value Survey Model)

Logically or intuitively a low score on the Masculinity-dimension ought to imply aggregated high values on the first two items, and low values on the last two. Because a replication of Hofstede's study has been carried through in Norway (Grenness, 2000), and data from that survey are available, it is possible to look further into this implication.

\section{Data source II: Results from a replication of Hofstede's Norwegian study}

During 1999, a replication of Hofstede's study was conducted in Norway (Grenness, 2000) . Although the sample was not directly comparable to Hofstede's, the validity of the study was assessed and found acceptable. The results on the Masculinity dimension confirmed Hofstede's conclusion: Norwegian managers still score low on this dimension. The size of the country sample (587 respondents) which contained a substantial percentage of women $(31.7 \%)$, also allowed for doing a meaningful break-down analyses e.g. with emphasize on the effect of gender. According to Hoppe (1990) this is not normally the case in comparative management studies due to the low percentage of female managers ordinary found in country samples, but in this case the size of the sample and the substantial percentage of women made this possible.

As was mentioned above, according to Hofstede, in highly feminine countries, differences between men and women on the Masculinty dimension is not to be expected due to the fact that in these countries both men and women may or may not be ambitious and competitive. Hofstede's assumption was only partly validated in Grenness' study as no significant gender differences were found regarding the scores on first two of the items making up the Masculinity dimension, while significant differences $(\mathrm{F}>3.84, \mathrm{p}<0.05)$ were found for the items "have an opportunity for advancements" and "have opportunity for high earnings". Still these differences are differences of a degree only. It is not so that Norwegian male managers tend to value advancement and earnings as important while females do not. Both value them as important, only the men tend to view them as even more important then the women (mean scores are 2.18 vs 2.43 , and 2.36 vs 2.57 respectively on a five point scale 
where 1 represents "of utmost importance"). Furthermore, an inspection of the full data set reveals that these are the typical responses of the individual respondents of the study as the standard deviations for these questions are generally small. Consequently, it looks like Hofstede was right about his predictions concerning (lack of) gender differences in extremely feminine countries like Norway.

In order to close in on the problem of how to draw sound conclusions on individuals from aggregated data, an individual as well as an ecological factor analyses of the data from Grenness' study were conducted. The general purpose of a factor analysis is to search for the underlying structure in a data set and express this in a few factors explaining as much of the variance as possible (Dunteman, 1989). In other words, factor analysis represents a tool for searching and defining the fundamental constructs or dimensions assumed to underlie the variables. With reference to Hofstede's research, conducting factor analysis on three different levels is possible: on total data, within groups (e.g. occupation or sex), and between groups (ecological factor analysis) (Hofstede, 1980, p. 81). According to Hofstede (op.cit) the total and within-group factor analysis gave very similar results, while the between-group factors were different from the other two. And he adds that for the total data / within-group analysis a Maslowian framework made sense. The ecological factor analysis, however, revealed two factors, which Hofstede labeled Individual/Collective and Social/Ego respectively which together accounted for $46 \%$ of the total variance of the country means. After reversing the positive and negative poles, the second factor became the basis for the Masculine-Feminine dimension.

Based on his own analysis, Hofstede's conclusion was that ecological and individual correlations are different and a confusion between the two is leading to the "ecological fallacy" (Hofstede, 1980).

As was stated in the introduction, the general acceptance of Hofstede's warning has severly reduced the usefulness of his study for those primarily interested in individual behavior. None the less, (Hoppe, 1990), in doing a replication of Hofstede, also conducted an individual factor analysis based on a hypothesis that country-level and individual-level analysis would generate conceptually different solutions. What he found was that the four factors of his individual factor analysis together explained $21 \%$ of the total variance of the data compared with $58 \%$ in the ecological analysis. The results of the individual factor analysis of Grenness' (Grenness, 2000) data, however, documented that together the four factors (four factors was decided because Hoppe as well as Hofstede used a four factor solution) explained $43.5 \%$ of the total variance. This is considerably higher than Hoppe's four factor solution. In order to explain this difference, we have to look at the differences between the two samples. It has to be pointed out that Hoppe's sample consisted of individuals from 19 countries, and although the respondents showed similarities (they were all alumni from the so-called Salzburg Seminars), they none the less represented different cultures as opposed to the single country sample in Grenness' study.

With relation to the problem concerning the "ecological fallacy", the most interesting result from Grenness' individual factor analysis is that the first factor (which explained $19 \%$ of the variance) consists of three of the items used for calculating the score on the Masculinity-dimension. Only the item "have security of employment" is not included. In addition we find three of four items used for calculating the score on the Individualism-dimension here, which suggests that the first factor resulting from an individual factor analysis combines the Masculinity-Individualism dimensions as they are defined by Hofstede. A direct comparison between the first factor of Grenness' study and Hofstede's two factors on which his Masculity and Individualsm indexes were based, show that six of eight items in this factor are items which are also found in Hofstede's two first factors. The factor, then, appear very similar to the country-level solution which - under certain conditions suggest a potential use of Hofstede's instrument at the individual level also.

Compared to Hofstede's own findings this result is somewhat surprising. Hofstede has on several occasions stated that his value dimensions are valid on an ecological level only, and in his replication (Hoppe, 1990) found only two factors based on the individual-level factor analysis which revealed constructs that were similar to those found on country level. The probable explanation for this, as has been pointed out above, is the differences between Grenness' and Hoppe's samples as Grenness' sample is drawn from one country only. The possible consequences of this sample difference may thus lead us to hypothesize that:

Avoiding the ecological fallacy is possible when the aggregated data are collected from groups or samples which are assumed to be or known to be homogenous, e.g. sharing dominant cultural values.

For example, comparative studies seem to verify that Norway is a country where management is based on values and norms such as equality, solidarity, and democracy (Grenness, 2000; Kalleberg, 1990; Revang \& Sørensen, 1994) which - among other things - have made Norwegians "the world champions of equality" according to a leading Norwegian business paper. This "passion" for equality constitutes a norm on the aggregated level 
(documented through e.g. a unitary school system and progressive taxation). It can be proposed, however, that this also holds on the individual (manager) level. This can be documented through the fact that not only do Norwegian managers receive lower pay than managers in other industrialized countries, also the gap between the pay of a manager and a blue collar worker is smaller than in any comparable country (Towers Perrin, 2000).

Another interesting observation is that Norwegian managers' values and norms seem to be fairly stable, as can be seen from the comparison of the means and standard deviations on the four masculinity items (discussed above) between Hoppe's (1990) Norwegian sample and Grenness' (2000) sample.

\section{Insert Table 2 here}

Even though the means differ somewhat, the standard deviations are remarkably similar indicating that the degree of homogeneity seems to be very stable.

\section{Data source III: results from a qualitative study of Norwegian managers}

A final source of documentation which may be used in order to validate conclusions on individuals based on aggregated data would be available and relevant studies on individual behavior. In the present case, a qualitative study of Norwegian managers (Grenness, 2003) revealed that Norwegian managers as individuals also value co-operation, consensus, participation, and power sharing. This can be taken as a rather strong indication that individual management behavior of Norwegian managers is in fact a manifestation of national cultural values This means that in this case national culture, as measured by Hofstede, can be viewed as an embedded component of organizations within that culture, and that individual management behavior is an inextricable, but also logical result of specific cultural values which are thought to be embedded within individual members and groups of members in a country (see e.g. Gibson, 1994).

\section{Discussion}

The method which has been described here may be regarded as rather "home-made" and arbitrary, but it none the less bares some resemblance to the method used by Price and Sanders (Macdonald \& Heath, 1996) which has been termed "pooling" aggregated and individual dataset, and to the method of "interrater agreement" (rwg) where the index is calculated by comparing the variance of a group's scores to an expected random variance (Bliese, 2000) in order to determine if .." reasonable consensus exists for a group to aggregate individual level data to the group level of analysis" (Dunlap, Burke, \& Smith-Crowe, 2003, p. 357). But mostly it resembles what has been known as "within and between analyses" (WABA) which can be used to show within-group similarity for a sample of respondents with respect to value orientations (Danserau \& Yammarino, 2000).

The study of value differences across cultures and the relationship of these differences to organizational behavior are of importance to both academics and practitioners. Understanding these relationships helps academics explain and prescribe effective management approaches for different environments, as well as helps international managers manage more effectively. In this connection Hofstede's cultural indices provide one approach that many academics and practitioners have found attractive. At the same time Hofstede's indices may have limited value for managers operating at the micro level.

For one thing, with reference to Grenness' (2000) country study, the necessity of considering the relationship of demographic variables such as sex, age and so forth to the indices ought to be considered. Also, as has been suggested by Latifi and Kiani (1997), using Hofstede as a base, it is possible to develop more "expressive" models for national culture. Such models take into consideration that within any country sub-cultures exist, and that the (work)values among individuals within such sub-cultures (e.g corporate cultures) may differ significantly from Hofstede's findings. Punnet and Withane (1990, p. 81) draw a similar conclusion based on the results of their examination of Hofstede's framework in three diverse samples, as they write: " In conclusion, it seems that the organizational culture may have had a substantial influence on all subjects' values".

\section{Conclusion}

Based on the above discussion it would of course be all too daring to propose that Hofstede was entirely wrong when he sent out his warning that his data were valid on an aggregated level only. On the other hand we think that his warning is probably it little too categorical and that it has reduced the value of his research unnecessary. Caution and sound judgment are always necessary ingredients when research results are to be interpreted. In order to assess the possibility of drawing methodological sound solutions on individual behavior where only aggregated data are available, we have suggested that knowledge about the degree of homogeneity (or heterogeneity) of the population in question is a vital factor. Based either on available values of the standard deviation (or similar measures of dispersion) of the population, and / or results of relevant studies of individual 
behavior of members of the group we have aggregated data on, or even general knowledge of demographics, we may draw conclusions that are more than pure guesswork.

In spite of the fact that statistical approaches exist which may help avoiding the ecological fallacy, we still think that non-statistical procedures like the ones we have proposed in this article are intuitively easier to understand, not least for managers. One repeating problem in cross-cultural research is that there are often two (or more) levels of theorizing that if not coordinated effectively into the research design may cause ecological fallacies. Consequently this is an important and often critical issue in cross-cultural research. Keeping in mind that one leading statistician has pronounced that "...The problems of confounding and aggregation bias, however, are unlikely to be resolved in the proximate future (Freedman, 1999, p. 5), we feel that a "fresh approach" towards this problem is at least worth trying for. None the less, it is important to bear in mind that judgment must be made case by case, focusing on the assumptions behind the methods. Only then will it be possible to convince the skeptics that inferences about individual behavior drawn for data about aggregates can not only be empirically right, but logically right as well.

\section{References}

Armstrong, R. W. (1996). The relationship between culture and perception of ethical problems in international marketing. Journal of Business Ethics, 15(11), 1199-1208. http://dx.doi.org/10.1007/BF00412818

Babbie, E. (1986). Values, opinions and identity. Paper presented at the American Sociological Association.

Blalock, H. M. (1964). Causal inferences in nonexperimental research. Chapel Hill, NC: University of North Carolina Press.

Blau, J. R., \& Blau, P. M. (1982). The Cost of Inequality - Metropolitan Structure and Violent Crime. American Sociological Review, 47(1), 114-129. http://dx.doi.org/10.2307/2095046

Bliese, P. D. (2000). Within-group agreement, non-independence, and reliability: Implications for data aggregation and analysis. In K.J.Klein \& S. W. J. Koslowski (Eds.), Multilevel Theory, Research, and Methods in Organizations (pp. 349 - 381). San Francisco: Jossey - Bass.

Bond, M. H. (2002). Reclaiming the individual from Hofstede's ecological analysis - A 20-year odyssey: Comment on Oyserman et al. (2002). Psychological Bulletin, 128(1), 73-77.

Cook, T. D., Fankhauser, G., Campbell, D. T., Reichardt, C. S., McCain, L. J., \& McCleary, R. (1979). Quasi-experimentation: design \& analysis issues for field settings. Boston: Houghton Mifflin Co.

Danserau, F., \& Yammarino, F. (2000). Within and between analysis. In K.J.Klein \& W. J. Kozlowski (Eds.), Multilevel Theory, research and methods in organizations (pp. 425-466). San Francisco: Jossey - Bass.

Dorfman, P. W., \& Howell, J. P. (1988). Dimensions of national culture and effective leadership patterns: Hofstede revisited. Advances in international comparative management, 3(127-150).

Dunlap, W. P., Burke, M. J., \& Smith-Crowe, K. (2003). Accurate tests of statistical significance for r(WG) and average deviation interrater agreement indexes. Journal of Applied Psychology, 88(2), 356-362. http://dx.doi.org/10.1037/0021-9010.88.2.356

Dunteman, G. H. (1989). Principal components analysis. Newbury Park, Calif.: Sage.

Firebaugh, G. (1978). A Rule for Inferring Individual-Level Relationships from Aggregate Data. American Sociological Review, 43(4), 557-572.

Frankfort-Nachmias, C., \& Nachmias, D. (1992). Research methods in the social sciences (4th ed.). New York: St. Martin's Press.

Freedman, D. A. (1999). Ecological inference and the ecological fallacy. International Encyclopedia of the Social \& Behavioral Sciences, 6, 4027-4030.

Gibson, C. B. (1994). The implications of national culture for organizational structure: an investigation of three perspectives. Advances in International Comparative Management, 9, 3-38.

Grenness, T. (2000). Perceptions of values and commitment of Norwegian managers. Unpublished thesis for the DBA. Brunel University/Henley Management College.

Grenness, T. (2003). Scandinavian Managers on Scandinavian Management. International Journal of Value-Based Management, 16(1), 9-21. http://dx.doi.org/10.1023/a:1021977514976

Grenness, T. (2011). Will the Scandinavian leadership model survive the forces of globalisation? A swot analysis. International Journal of Business and Globalisation, 7(3), 332-350. 
http://dx.doi.org/10.1504/ijbg.2011.042062

Halle, N. H. (1976). Noen feilslutninger i forbindelse med korrelasjon. In S. U. Larsen (Ed.), Problemer $i$ samfunnsvitenskapelig metode. Bergen: Universitetsforlaget.

Higgs, G. B., Higgs, G., Bellin, W., Farrell, S., \& White, S. (1997). Educational Attainment and Social Disadvantage: Contextualizing School League Tables. Regional Studies, 31(8), 775-789. http://dx.doi.org/10.1080/00343409750129607

Hofstede, G. (1980). Culture's consequences: international differences in work-related values. Beverly Hills, Calif.: Sage.

Hofstede, G. (1991). Cultures and organizations: software of the mind. London: McGraw-Hill.

Hofstede, G. (2011). Hofstede and Migliore - rebuttal and response. Cross Cultural Management: An International Journal, 18(3).

Hofstede, G., \& McCrae, R. R. (2004). Personality and culture revisited: Linking traits and dimensions of culture. Cross-cultural research, 38(1), 52-88. http://dx.doi.org/10.1177/1069397103259443

Hoppe, M. H. (1990). A comparative study of country elites: international differences in work-related values and learning and their implications for management training and development. Doctoral Dissertation. University of North Carolina. Chapel Hill.

Kalleberg, R. (1990). Scandinavian in a comparative perspective. Paper, University of Oslo, Department of Sociology.

King, G. (1997). A solution to the ecological inference problem: reconstructing individual behavior from aggregate data. Princeton: Princeton University Press.

Kitayama, S. (2002). Culture and basic psychological processes - Toward a system view of culture: Comment on Oyserman et al. Psychological Bulletin, 128(1), 89-96. http://dx.doi.org/10.1037/0033-2909.128.1.89

Langbein, L. I., \& Lichtman, A. J. (1979). Ecological inference. Thousand Oaks, Ca: Sage.

Latifi, F., Kiani, G. R., \& Henley Management College. Henley Research, C. (1997). An expressive model to interpret multi-faceted cultures: an application for strategic planning in Iran. Henley-on-Thames: Henley Management College.

Macdonald, K., \& Heath, A. (1996). Pooling Cross-Sections: a Comment on Price and Sanders. Political Studies, 45: 928-941.

Migliore, L. A. (2011). Relation between big five personality traits and Hofstede's cultural dimensions Samples from the USA and India. Cross Cultural Management-an International Journal, 18(1), 38-54. http://dx.doi.org/10.1108/13527601111104287

Punnett, B. J., \& Withane, S. (1990). Hofstede's Value Survey Module: to embrace or abandon? Advances in international comparative management, 5, 69-89.

Revang, Ø., \& Sørensen, B. A. (1994). Ledelse og management i norsk sammenheng: historiske betraktninger og fremtidige utfordringer. Sandvika: Norwegian School of Management.

Robinson, R. (1983). Book Reviews: G. Hofstede, Culture's Consequence. Work and Occupations, 10, 110-115.

Robinson, W. S. (1950). Ecological Correlations and the Behavior of Individuals. American Sociological Review, 15(3), 351-357.

Schaffer, B. S., \& Riordan, C. M. (2003). A review of cross-cultural methodologies for organizational research: A best-practices approach. Organizational Research Methods, 6(2), 169-215. http://dx.doi.org/10.1177/1094428103251542

Schramm Nielsen, J., Sivesind, K. H., \& Lawrence, P. (2004). Management in Scandinavia: culture, context and change. Cheltenham: Edward Elgar.

Schwartz, S. (1994). The Fallacy of the Ecological Fallacy - the Potential Misuse of a Concept and the Consequences. American Journal of Public Health, 84(5), 819-824. http://dx.doi.org/10.2105/AJPH.84.5.819

Smith, P. B., Peterson, M. F., \& Schwartz, S. H. (2002). Cultural values, sources of guidance, and their relevance to managerial behavior. Journal of cross-cultural Psychology, 33(2), 188-208. http://dx.doi.org/10.1177/0022022102033002005 
Table 1. Matrix showing nine theoretical situations where empiracally valid or invalid (buit logically invalid) conclusions can be drawn concerning the correlation between $\mathrm{x}$ and $\mathrm{y}$ across levels of analysis (adapted from Halle, 1976)

\begin{tabular}{|c|c|c|c|c|}
\hline LEVEL & Ecological $(n+1)$ & Individual ( $\mathrm{n}$ ) & From $(n+1)$ to $(n)$ & $\begin{array}{l}\text { Conclusion is } \\
\text { empirically valid }\end{array}$ \\
\hline \multirow[t]{9}{*}{ Correlation is: } & + & + & + & yes \\
\hline & + & - & + & no \\
\hline & + & 0 & + & no \\
\hline & - & + & - & no \\
\hline & - & - & - & yes \\
\hline & - & 0 & - & no \\
\hline & 0 & - & 0 & no \\
\hline & 0 & + & 0 & no \\
\hline & 0 & 0 & 0 & yes \\
\hline
\end{tabular}

Table 2. Comparison of means and standard deviations on the four Masculinity items between Hoppe's and Grenness' studies

\begin{tabular}{|l|l|l|l|l|}
\hline & \multicolumn{3}{|l|}{ GRENNESS (2000) } & HOPPE (1990) \\
\hline Items & Mean & Std & Mean & Std \\
\hline 1. (Work with people..) & 2.64 & 0.78 & 2.38 & 0.79 \\
\hline 2. (Have security..) & 2.11 & 0.75 & 1.91 & 0.64 \\
\hline 3. (Advancements..) & 2.25 & 0.92 & 2.88 & 0.77 \\
\hline 4. (Higher earnings..) & 2.43 & 0.77 & 2.59 & 0.84 \\
\hline
\end{tabular}

